\title{
A career in child and adolescent psychiatry? Survey of trainees' views
}

\section{AIMS AND METHOD}

The aim of the study was to elicit the views of senior house officers in psychiatry across London regarding the factors that influence their decision whether to pursue a career in child and adolescent psychiatry. Postal questionnaires were sent to a random sample of all senior house officers on London psychiatry training schemes.

\author{
RESULTS \\ Of the respondents who recalled \\ being taught child psychiatry at \\ medical school, $91 \%$ found it inter- \\ esting and $73 \%$ found it useful. of \\ those who recalled having such \\ teaching during psychiatric training, \\ $90 \%$ found it interesting and $85 \%$ \\ found it useful. However, this had no \\ significant impact upon subsequent \\ career choice. Experience of working \\ as a senior house officer in child psy- \\ chiatry did influence future career
}

intentions. Trainees who identified such placements as providing good clinical experience or job satisfaction were significantly more likely to consider the specialty for a future career.

\section{CLINICAL IMPLICATIONS}

Consultants and managers should create and maintain senior house officer posts that will encourage trainees to perceive the specialty as a future career.
Psychiatry has been experiencing recruitment difficulties both at consultant and specialist registrar level for a number of years. Recent census data indicate that the consultant vacancy rate has been fairly static for child and adolescent psychiatry over the past 3 years for which data are available. However, although the overall consultant vacancy rate for child psychiatry in England in 2001 was $7.3 \%$, lower than nearly all the other psychiatric specialties, within London the rate was 9.5\% (Royal College of Psychiatrists, 2002)

There is an awareness of the need to develop services to meet the mental health needs of our children and adolescents (Department of Health, 2004a). Many of these proposed developments come with an expectation of increased funding for child and adolescent mental health services (CAMHS) and the possibility of a real expansion in consultant post numbers. In the meantime, we are experiencing increasing pressure in $\mathrm{CAMHS}$ with referral rates rising each year (Department of Health, 2004b). Although increasing effort is being dedicated to meeting this need, the inability to appoint to new consultant and specialist registrar posts is not an unfamiliar experience, particularly in London. In contrast to many other medical specialties, the Department of Health identified only 0.8 applicants for each specialist registrar post in child psychiatry (Department of Health, 2002).

Although historically psychiatry has responded to recruitment problems by focusing on the undergraduate curriculum, improvements in attitudes towards psychiatry are generally not maintained (Brockington et al, 2002) This is despite the increasing share of curriculum time, introduction of modern teaching methods and the establishment of chairs in psychiatry at almost all medical schools. Others concur that further increases in time devoted to psychiatry at undergraduate level would not be cost-effective (Storer, 2002).

Pidd (2003) suggests that undergraduate experiences should be positive and that we should identify and nurture interested students through to senior house officer posts. She notes that for all medical specialties, retaining consultants would make the biggest difference to vacancy rates. Yet the survey by Littlewood et al (2003) of child mental health professionals in north-east England found high levels of anxiety, worry and time off as a result of stress constituted a poor model for potential trainees.

Brockington et al (2002) recommend that research should focus on why graduates choose psychiatry after their preregistration year. We therefore decided to elicit the views of senior house officers regarding the factors that influence their decision whether or not to pursue a career in child and adolescent psychiatry, in order to help us identify where to target training most effectively.

\section{Method}

A list of all senior house officer posts on London psychiatry training schemes $(n=625)$ was obtained from senior house officer programme directors and postgraduate medical education administrators and numbered from 1 to 625. Postal questionnaires were sent to 240 posts randomly sampled from the total by a computer program (Statistical Package for Social Sciences for Windows (SPSS), version 12.01). A second copy of the questionnaire was sent to non-respondents after a further 6 weeks.

The questionnaire covered basic demographic details including gender, age, and number of years working in psychiatry. Experience of, and satisfaction with, child psychiatry teaching at different stages of training were explored. Respondents were asked whether or not they had received teaching in the specialty at medical school or during general psychiatry senior house officer training, and whether the teaching received had been interesting or useful. Those who had completed a specific senior house officer post in child and adolescent psychiatry were asked to rate aspects of the job, including clinical experience, supervision, learning opportunities and job 
satisfaction. All respondents were asked whether they would consider a career in child and adolescent psychiatry

original papers

and to give reasons for or against such a decision. This is a newly developed questionnaire and its reliability and validity are untested. (A copy of the questionnaire is available from the authors on request.)

Responses were compared in order to try to identify whether exposure to child psychiatry teaching at any particular stage of a junior doctor's career would impact upon subsequent career intentions.

Data were analysed using SPSS, version 12.01. Data are presented in terms of number counts (frequencies) and percentages, and means and standard errors where appropriate. In bivariate analysis, the Pearson's $\chi^{2}$ test was used to measure associations between categorical variables.

\section{Results}

There were 153 questionnaires returned (64\%); 55\% of respondents were male, $45 \%$ female with an age range of $24-48$ years.

There were 55 respondents (36\%) that said they would consider a career in child psychiatry, $44(29 \%)$ that said they would not, 52 (34\%) were unsure and 2 (1\%) omitted to answer the question. Neither gender nor age made any statistical difference to the stated career intention.
There were 67 respondents (44\%) that recalled having received teaching in child psychiatry while at medical school, whereas 77 (51\%) declared receiving none and 7 (5\%) left the question unanswered. Of those who did have some teaching at this stage, 43 (64\%) thought that this was sufficient, 61 (91\%) found the teaching interesting and $49(73 \%)$ found it useful. There was no statistical difference between those who reported having child psychiatry teaching at undergraduate level and a subsequent intention to consider a career in the specialty (Table 1).

There were 103 (68\%) respondents that reported receiving some child psychiatry teaching during the course of their psychiatric training; 45 (30\%) did not receive such training and $3(2 \%)$ did not answer the question. The most common sources of this training were the MRCPsych course, a local academic programme and child psychiatry placements. Of those who did have some teaching at this stage, 93 (90\%) found the teaching interesting and 87 (85\%) found it useful. Again, there was no statistical difference found between those who reported having child psychiatry teaching at postgraduate level and a subsequent intention to consider a career in the specialty (Table 1).

There were $62(41 \%)$ senior house officers that reported having worked in a child psychiatry placement. We found that those senior house officers who have completed a placement in child psychiatry are

Table 1. Impact of child psychiatry teaching at different stages of training upon career preference

\begin{tabular}{|c|c|c|c|c|c|c|}
\hline & \multicolumn{6}{|c|}{ Consider career in child psychiatry? $(n=151)$} \\
\hline & $\begin{array}{l}\text { Yes } \\
n(\%)\end{array}$ & $\begin{array}{l}\text { No } \\
n(\%)\end{array}$ & $\begin{array}{l}\text { Unsure } \\
n(\%)\end{array}$ & $\chi^{2}$ & d.f. & $P$ \\
\hline \multicolumn{7}{|l|}{ Teaching at medical school } \\
\hline Yes & $27(18)$ & $19(13)$ & $21(14)$ & \multirow{2}{*}{0.828} & \multirow{2}{*}{2} & \multirow[b]{2}{*}{0.661} \\
\hline No & $26(17)$ & $22(15)$ & $29(19)$ & & & \\
\hline \multicolumn{7}{|l|}{ Teaching during psychiatry training } \\
\hline Yes & $38(25)$ & $33(22)$ & $32(21)$ & \multirow{2}{*}{2.185} & \multirow{2}{*}{2} & \multirow{2}{*}{0.335} \\
\hline No & $16(11)$ & $10(7)$ & $19(13)$ & & & \\
\hline \multicolumn{7}{|l|}{ Child psychiatry SHO placement } \\
\hline Yes & $20(13)$ & $25(17)$ & $17(11)$ & \multirow{2}{*}{6.721} & \multirow{2}{*}{2} & \multirow{2}{*}{0.035} \\
\hline No & $34(23)$ & $18(12)$ & $34(23)$ & & & \\
\hline \multicolumn{7}{|l|}{$1-2$ years psychiatry training $(n=76)$} \\
\hline Child psychiatry SHO placement & $6(8)$ & $2(3)$ & $5(7)$ & \multirow{2}{*}{0.305} & \multirow[b]{2}{*}{2} & \multirow[b]{2}{*}{0.858} \\
\hline No child psychiatry SHO placement & $24(31)$ & $12(16)$ & $27(35)$ & & & \\
\hline \multicolumn{7}{|l|}{$3-4$ years psychiatry training $(n=72)$} \\
\hline Child psychiatry SHO placement & $14(19)$ & $23(32)$ & $12(17)$ & \multirow[b]{2}{*}{2.943} & \multirow[b]{2}{*}{2} & \multirow{2}{*}{0.230} \\
\hline No child psychiatry SHO placement & $10(14)$ & $6(8)$ & $7(10)$ & & & \\
\hline
\end{tabular}

Table 2. Experience of child psychiatry as a senior house officer placement

\begin{tabular}{|c|c|c|c|c|}
\hline & $\begin{array}{l}\text { Poor } \\
n(\%)\end{array}$ & $\begin{array}{l}\text { Average } \\
n(\%)\end{array}$ & $\begin{array}{l}\text { Good } \\
n(\%)\end{array}$ & $\begin{array}{l}\text { No response } \\
n(\%)\end{array}$ \\
\hline Clinical experience & $8(13)$ & $25(40)$ & $28(45)$ & $1(2)$ \\
\hline Supervision & $8(13)$ & $15(24)$ & $38(61)$ & $1(2)$ \\
\hline Learning opportunities & $6(10)$ & $15(24)$ & $39(63)$ & $2(3)$ \\
\hline
\end{tabular}


Table 3. Impact of experience of child psychiatry during a senior house office placement upon career preference

\begin{tabular}{|c|c|c|c|c|c|c|c|}
\hline & \multicolumn{7}{|c|}{ Consider career in child psychiatry? $(n=62)$} \\
\hline & $\begin{array}{l}\text { Yes } \\
n(\%)\end{array}$ & $\begin{array}{l}\text { No } \\
n(\%)\end{array}$ & $\begin{array}{l}\text { Uncertain } \\
n(\%)\end{array}$ & $\begin{array}{l}\text { Total } \\
n(\%)\end{array}$ & $\chi^{2}$ & d.f. & $P$ \\
\hline \multicolumn{8}{|c|}{ Clinical experience } \\
\hline Poor/average & $6(10)$ & $19(31)$ & $8(13)$ & $33(53)$ & \multirow{2}{*}{8.516} & \multirow{2}{*}{2} & \multirow{2}{*}{0.014} \\
\hline Good & $14(23)$ & $7(11)$ & $8(13)$ & $29(47)$ & & & \\
\hline \multicolumn{8}{|l|}{ Supervision } \\
\hline Poor/average & $8(13)$ & $10(16)$ & $5 \quad(8)$ & $23(37)$ & \multirow{2}{*}{0.327} & \multirow{2}{*}{2} & \multirow{2}{*}{0.849} \\
\hline Good & $12(19)$ & $16(26)$ & $11(18)$ & $39(63)$ & & & \\
\hline \multicolumn{8}{|c|}{ Learning opportunities } \\
\hline Poor/average & $5 \quad(8)$ & $10(16)$ & $6(10)$ & $21(34)$ & \multirow{2}{*}{0.808} & \multirow{2}{*}{2} & \multirow{2}{*}{0.668} \\
\hline Good & $14(23)$ & $16(26)$ & $10(16)$ & $40(66)$ & & & \\
\hline \multicolumn{8}{|l|}{ Job satisfaction } \\
\hline Poor/average & $9(15)$ & $22(35)$ & $12(19)$ & $43(69)$ & \multirow{2}{*}{8.670} & \multirow{2}{*}{2} & \multirow{2}{*}{0.013} \\
\hline Good & $11(18)$ & $4(6)$ & $4(6)$ & $19(31)$ & & & \\
\hline
\end{tabular}

original papers significantly less likely to identify the specialty as a future career intention (Table 1). However, this finding becomes statistically insignificant when length of time working in psychiatry is taken into account (Table 1). Their experience of such a placement is shown in Table 2 .

Trainees who identified their placements as providing 'good' as opposed to 'poor/average' clinical experience or job satisfaction were significantly more likely to identify child psychiatry as a future career intention (Table 3). Supervision and learning opportunities showed no such impact.

Of those who would consider a career in child psychiatry, the most popular reasons identified for considering the specialty included, in order of frequency:

(1) interesting work;

(2) age range of patients;

(3) multidisciplinary work;

(4) psychological treatments;

(5) different theorectical approaches;

(6) making a difference at an early age;

(7) developmental psychopathology.

Of those who would not consider a career in child psychiatry, the most frequent reasons identified for not considering the specialty included, in order of frequency:

(1) social factors limiting effectiveness;

(2) lack of experience working with children;

(3) lack of opportunity to use medical skills;

(4) lack of resources.

\section{Discussion}

Our results show that $70 \%$ of trainees recalled having no teaching or insufficient teaching of child psychiatry at medical school. It is surprising that more than half recalled having no such teaching within their undergraduate years given that we would expect this to be covered by most UK medical school curricula. One possible explanation for this finding is that overseas graduates may be well represented among senior house officers in psychiatry (Tyrer et al, 2002) and that such trainees may have had less exposure to child psychiatry teaching at an undergraduate level. However, our data do not enable us to examine this further.

Those who did receive teaching generally found it to be interesting and useful, indicating that satisfaction with the quality of teaching received at this point in training is good. Although this might indicate that we should ensure that more students receive adequate teaching at medical school, the lack of any connection between teaching received and future career intentions regarding child psychiatry indicates that targeting teaching at this level will have little impact upon future recruitment into the specialty. Whereas previous research has demonstrated that positive attitudes towards psychiatry at the end of undergraduate education influence career choice (Cottrell, 1999), our findings suggest that sub-specialty teaching has more influence at a later career stage. This is in line with government policy which recommends that teaching at undergraduate level should not be with a view to creating specialists.

Most senior house officers received some exposure to child psychiatry teaching within their general psychiatric training. Again, satisfaction with this teaching is good but has no impact upon future career intention in favour of the specialty. Hence, targeting more or better teaching at this stage is also unlikely to have a significant impact upon recruitment.

Our results indicate that most senior house officers are happy with various aspects of such posts in child psychiatry. However, more experienced trainees, i.e. those with 3-4 years training in psychiatry, particularly those who have completed a child psychiatry post, are less likely to consider a career in the specialty. This suggests that we might need to reconsider the structure of such posts so that trainees maximise their clinical experience and opportunities for job satisfaction. These results emphasise the importance placed by Pidd (2003) and Halford (2003) upon positive training experiences and the doctors' well-being. Compared with other psychiatric specialties, senior house officers in child psychiatry often find themselves to have less of a clear role. The skills required for child psychiatry often seem different to those developed on adult in-patient units, leaving trainees feeling underutilised and redundant. We 
suggest that the onus is on the consultant supervisor to ensure that the senior house officers are given a useful

original

papers

role within the team, and are exposed to the wide variety of conditions seen in child mental health services.
One of the limitations of this study is that it is of a retrospective nature. Ideally, a prospective study involving trainees embarking upon a training scheme would give additional information. Additional limitations include the nature of the reported information which is based upon recollections that may not be entirely accurate.

We have not identified a sole cause for poor recruitment to our specialty, and as in other specialties of medicine we are dependent upon broader societal factors influencing career intentions. However, our findings do indicate that, from the perspective of recruitment, teaching and training in child psychiatry should be targeted at senior house officers working with us in our clinics, rather than at the undergraduate or general postgraduate level. Of course, recruitment is not the only purpose of teaching. We do acknowledge that most undergraduates and graduates will not pursue careers in child psychiatry but will nevertheless benefit from teaching in the specialty in order to improve their understanding of the relevant pathology. We would not therefore propose targeting child psychiatry senior house officers for training at the expense of teaching elsewhere. However, to improve recruitment into the specialty, consultants and managers have a responsibility to create and maintain conditions that will encourage trainees to perceive child psychiatry as a future career.

\section{Declaration of interest}

None.

\section{References}

BROCKINGTON, I. F. \& MUMFORD, D. B. (2002) Recruitment into psychiatry. British Journal of Psychiatry, 180 307-312.

COTTRELL, D. (1999) Recruitment, undergraduate education and the possible impact of tomorrow's doctors. Psychiatric Bulletin, 23, 582-584.

DEPARTMENT OF HEALTH (2002)

Unfinished Business - Proposals for the Reform of the Senior House Officer Grade. London: Department of Health.

DEPARTMENT OF HEALTH (2004a)

National Service Framework for

Children, Young People and Maternity

Services, Child and Adolescent Mental Health (CAMHS). London: Department of Health.

DEPARTMENT OF HEALTH (2004b) Child and Adolescent Mental Health Service Mapping, 2003. London: Department of Health.

HALFORD, J. (2003) Invited commentary on: Recruiting and

retaining psychiatrists. Advances in Psychiatric Treatment, 9, 411-413.

LITTLEWOOD, S., CASE, P., GATER, R., et al (2003) Recruitment, retention, satisfaction and stress in child and adolescent psychiatrists. Psychiatric Bulletin, 27, 61-67.

PIDD, S. A. (2003) Recruiting and retaining psychiatrists. Advances in PsychiatricTreatment, 9, 405-411.

ROYAL COLLEGE OF PSYCHIATRISTS (2002) Annual Census of Psychiatric Staffing, 2001 (Occasional Paper OP54). London: Royal College of Psychiatrists.

STORER, D. (2002) Recruiting and retaining psychiatrists. British Journal of Psychiatry, 180, 296-297.

TYRER, S. P., LEUNG, W.-C., SMALLS, J., et al (2002) The relationship between medical school of training, age, gender and success in the MRCPsych examinations. Psychiatric Bulletin, 26, 257-263.

*Graeme Lamb Consultant in Child and Adolescent Psychiatry, Newham Child and Family Consultation Service, York House, 411 Barking Road, London E13 8AL, e-mail: Graeme.Lamb@ELCMHT.NHS.UK, Navina Evans Consultant in Child and Adolescent Psychiatry, Newham Child and Family Consultation Service, David Baillie Specialist Registrar in Psychiatry, St Bartholomew's and Royal London Specialist RegistrarTraining Scheme 